\title{
KEPENTINGAN PETAHANA DALAM MANIPULASI PILKADA LABUHAN BATU SELATAN 2015
}

\author{
Amri Yusra dan Ikhsan Darmawan \\ Departemen Ilmu Politik Universitas Indonesia \\ E-mail: amriyusra.depok@gmail.com
}

\begin{abstract}
ABSTRAK
Etika penyelenggara pemilu telah diatur dengan Peraturan Bersama di mana ketika peraturan itu dilanggar, maka penyelenggara pemilu itu dapat diberi sanksi sampai yang terberat: pemberhentian tetap. Meskipun demikian, peraturan ketat itu tidak berhasil membuat tidak terjadi manipulasi dalam Pilkada Labuhan Batu Selatan 2015. Adanya tindakan manipulasi dalam Pilkada Labuhan Batu Selatan mengakibatkan Dewan Kehormatan Penyelenggara Pemilu (DKPP) mengeluarkan putusan pemberhentian tetap kepada empat orang penyelenggara Pilkada Labuhan Batu Selatan 2015. Artikel ini bertujuan untuk menjawab pertanyaan: 'Mengapa terjadi manipulasi dalam Pilkada Labuhan Batu Selatan tahun 2015?" Dengan menggunakan metode kualitatif serta pengumpulan data melalui wawancara mendalam dan studi dokumen, artikel ini menjelaskan bagaimana konteks awal terjadinya manipulasi, proses-proses yang terjadi setelahnya saat Pilkada berlangsung, dan penjelasan mengapa terjadi manipulasi disertai analisis dengan menggunakan kerangka teori manipulasi Pemilu. Sedikit berbeda dengan argumen pada umumnya bahwa manipulasi dalam pemilu terjadi karena adanya kepentingan memastikan kemenangan petahana agar bisa melewati batas menang minimal, artikel ini berargumen bahwa manipulasi dalam Pilkada Labuhan Selatan tahun 2015 disebabkan adanya kepentingan memenangkan petahana yang didukung oleh adanya kelemahan dalam aturan tentang proses rekrutmen penyelenggara Pilkada.
\end{abstract}

Kata kunci: manipulasi pemilu, Pilkada, Labuhan Batu Selatan, petahana, regulasi pemilu

\section{THE INTEREST OF INCUMBENT IN MANIPULATION OF LABUHAN BATU SELATAN LOCAL ELECTION 2015}

\begin{abstract}
The ethics of election officer has been ruled by the Law. When it is violated by the election officers, then they can be punished by being terminated. However, the stringent rule cannot stop the manipulation in Labuhan Batu Selatan Local Election 2015 happened. As a result, DKPP released termination punishment to four election officers of Labuhan Batu Selatan. This article aims at answering the question: "Why did manipulation happen in Labuhan Batu Selatan Local Election 2015?" By using the qualitative method, depth interviews and document study as the method of data collection, this article explains how was the preliminary context of the election manipulation, the processes happened after that when the Election happened, and the explanation why did manipulation happen with the analysis using the theory of election manipulation. A little different with the argument that manipulation in an election generally conducted to ensure the winning of incumbent so that he can pass the minimum percentage of winning, this article argues that manipulation in Labuhan Batu Selatan Local Election 2015 was caused by the interest of winning the incumbent which is supported by the weaknesses in regulation about recruitment of local election officer.
\end{abstract}

Key words: election manipulation, local election, South Labuhan Batu, incumbent, electoral regulation

\section{PENDAHULUAN}

Di dalam studi tentang pemilu, analisis tentang manipulasipemilu dinegara demokratis masih relatif terbatas. Keterbatasan tersebut disebabkan salah satunya karena manipulasi pemilu identik dengan negara non-demokratis (Beaulieu dan Hyde, 2009), seperti misalnya di Rusia dan Venezuela (Simpser, 2013).
Terlebih lagi, penelitian manipulasi pemilu yang mengambil studi kasus di Indonesia jarang dilakukan karena Indonesia sejak tahun 1999 sampai dengan tahun 2015 menunjukkan arah menuju negara demokratis. Sebab lainnya adalah karena penelitian yang pernah dilakukan terkait manipulasi pemilu biasanya lebih bertalian dengan aspek hukum dan cara memanipulasi pemilu (ilmu komputer) 
ketimbang ilmu politik. Kalaupun ada studi pemilu yang berkenaan dengan manipulasi pemilu, tidak secara langsung menyebutkan manipulasi pemilu, melainkan lebih kepada penelitian etika penyelenggara pemilu (Firman, 2015; Sasongko, 2015; Sarnan, 2015; Darwis, 2015).

Berkaitan dengan itu, salah satu ciri pemilihan umum yang ideal adalah bahwa dalam proses berjalannya pemilu harus berjalan prinsip transparan, imparsial, dan terbebas dari manipulasi politik sejak sebelum pemilu sampai dengan akhir proses terhadap hasil pemilu (Goodwin-Gill, 2006: 46; lihat juga Yuningsih dan Subekti, 2015). Untuk menjamin tercapainya prinsip-prinsip tadi, eksistensi aturan pemilu memegang peranan penting (Elklit dan Svensson, 1997). Indonesia telah memiliki peraturan terkait dengan nama Peraturan Bersama KPU, Bawaslu, dan DKPP tentang Kode Etik Penyelenggara Pemilu. Keberadaan peraturan tersebut adalah untuk menegakkan kode etik terhadap para penyelenggara pemilu (Asshiddiqie, 2013). Dalam aturan tersebut disebutkan sejumlah sanksi yang dapat diberikan kepada penyelenggara pemilu yang melanggar kode etik, yakni dari mulai teguran tertulis sampai dengan pemberhentian tetap.

Akan tetapi, pada kenyataannya, adanya Peraturan Bersama itu ternyata tidak sertamerta membuat tiap penyelenggara takut untuk melanggarnya. Berdasarkan data Dewan Kehormatan Penyelenggara Pemilu (DKPP), sampai dengan tahun 2015, terdapat 953 teradu yang diputuskan mendapatkan sanksi. Dari jumlah keseluruhan tersebut, 26,14\% di antaranya memperoleh saksi terberat, yaitu pemberhentian tetap (Laporan Puskapol UI, 2016).

Artikel ini membahas tentang kasus manipulasi pemilu dalam Pilkada Labuhan Batu Selatan tahun 2015. Menurut Putusan DKPPNo. 70/DKPP-PKE-IV/2015, empat orang anggota KPU Labuhan Batu Selatan (Imran Husaini Siregar, Irwansyah, Khairul Mubarrik Harahap, dan Salim) diputuskan untuk diberhentikan tetap sebagai penyelenggara pemilu. Putusan itu dikeluarkan terkait aduan tentang kasus dikeluarkannya Keputusan Tidak Memenuhi Syarat sebagai calon Bupati Labuhan Batu Selatan sebelum tanggal semestinya dan dilanjutkan dengan tindakan tidak memasukkan PDI-Perjuangan sebagai pengusung pasangan calon Usman dan Arwi Winata. Penulis berpendapat bahwa tindakan-tindakan yang dilakukan oleh empat orang anggota KPU Labuhan Batu Selatan termasuk ke dalam kategori tindakan manipulasi pemilu, yaitu creating obstacles to candidate registration (melakukan tindakan menyulitkan dalam pendaftaran calon) (Simpser, 2013: 35-36). Tindakan yang berusaha untuk menggagalkan pencalonan terhadap bakal calon dapat dikategorikan sebagai tindakan manipulasi pemilu (Bachriadi, et.al., 2015: 223)

Kasus Labuhan Batu Selatan dalam Pilkada tahun 2015 dipilih di antara kasuskasus lainnya karena beberapa sebab. Pertama, Kabupaten Labuhan Batu Selatan berada di Provinsi Sumatera Utara di mana berdasarkan data kuantitatif, selama kurun waktu 2013-2015, provinsi tersebut adalah daerah kedua dengan jumlah pengaduan pelanggaran etika tertinggi setelah Jawa Timur (Puskapol UI, 2016). Kedua, kasus Labuhan Batu Selatan termasuk kategori extreme case karena mayoritas (empat dari lima orang) anggota KPU-nya diberhentikan tetap oleh DKPP. Bahkan, satu orang anggota KPU Labuhan Batu Selatan yang tidak diberhentikan tetap juga mendapatkan sanksi berupa peringatan keras. Jumlah mayoritas yang diberi sanksi berat seperti disebutkan di atas menunjukkan adanya kesalahan serius yang dilakukan sehingga DKPP mengeluarkan putusan tersebut.

Berangkat dari pemaparan di atas, artikel ini menjawab pertanyaan: 'Mengapa terjadi manipulasi dalam Pilkada Labuhan Batu Selatan tahun 2015?"Artikel ini bertujuan untuk menjelaskan bagaimana konteks awal terjadinya manipulasi, proses-proses yang terjadi setelahnya saat Pilkada berlangsung, dan penjelasan mengapa terjadi manipulasi disertai analisis dengan menggunakan kerangka teori yang relevan. Pada umumnya, penelitianpenelitian tentang manipulasi pemilu berkesimpulan bahwa manipulasi pemilu dilakukan karena adanya kepentingan dari calon petahana untuk memenangi pemilu (Simpser, 2013; Hyden and Leys, 1972; Sakwa and Crouch, 1978; Lewis, 1990; Anderson, 1996; Taylor, 1996). Penulis sedikit berbeda dengan argumen-argumen pada umumnya seperti diuraikan di atas. Jika pada studi-studi sebelumnya manipulasi dalam sebuah pemilu dilakukan untuk kepentingan memastikan 
kemenangan Petahana agar bisa melewati batas menang minimal, maka artikel ini berargumen bahwa manipulasi dalam Pilkada Labuhan Selatan tahun 2015 disebabkan adanya kepentingan memenangkan petahana yang didukung oleh adanya kelemahan dalam aturan tentang proses rekrut-men penyelenggara Pilkada.

Pembahasan dalam artikel ini akan menggunakan teori sebab terjadinya manipulasi pemilu. Istilah manipulasi pemilu, khususnya dalam pemilu di Indonesia saat ini, lebih jarang digunakan ketimbang istilah pelanggaran pemilu. Hal ini dikarenakan istilah manipulasi pemilu identik dengan rezim nondemokratis, seperti di Iran pada Pemilu 2009, di Belarusia, Kazakhstan, Nigeria, Zambia, Zimbabwe, Yaman, Meksiko di bawah PRI, dan Paraguay di bawah Stroessner (Simpser, 2013), sementara pelanggaran pemilu (electoral fraud) dapat terjadi di rezim manapun. Cavdar (dalam Alvarez et.al., 2008) mendefinisikan pelanggaran pemilu sebagai "usaha melanggar prosedur pemilu secara illegal dan disengaja", sedangkan manipulasi pemilu adalah "Tindakantindakan yang ditujukan untuk mengeksekusi kontrol terhadap sistem pemilu, hasil dan maknanya". Selain itu, dibandingkan dengan pelanggaran pemilu, manipulasi pemilu memiliki kesan sebagai sebuah kegiatan yang terencana dan dampak maupun tindakannya bersifat massif. Sementara itu, pelanggaran pemilu bersifat sebaliknya.

Tabel 1. Perbedaan Manipulasi Pemilu dan Pelanggaran Pemilu

\begin{tabular}{ll}
\hline \multicolumn{1}{c}{ Manipulasi Pemilu } & Pelanggaran Pemilu \\
\hline $\begin{array}{l}\text { Tindakan-tindakan } \\
\text { yang ditujukan untuk } \\
\text { mengeksekusi kontrol } \\
\text { terhadap sistem pemilu, } \\
\text { hasil dan maknanya }\end{array}$ & $\begin{array}{l}\text { Usaha melanggar } \\
\text { prosedur pemilu } \\
\text { secara illegal dan } \\
\text { disengaja }\end{array}$ \\
$\begin{array}{l}\text { Identik dengan rezim non- } \\
\text { demokratis }\end{array}$ & $\begin{array}{l}\text { Dapat terjadi di } \\
\text { rezim demokratis } \\
\text { dan non-demokratis }\end{array}$ \\
$\begin{array}{l}\text { Kegiatan yang bersifat } \\
\text { terencana }\end{array}$ & $\begin{array}{l}\text { Dapat terencana } \\
\text { maupun tidak }\end{array}$ \\
Dampaknya bersifat massif & $\begin{array}{l}\text { Dampaknya } \\
\text { terbatas di tempat } \\
\text { pelanggaran terjadi }\end{array}$ \\
\hline
\end{tabular}

Sumber: Diolah penulis dari berbagai sumber.

Manipulasi pemilu dapat didefinisikan sebagai "An act that potentially affects election result"- Sebuah tindakan yang berpotensi mempengaruhi hasil pemilu (Lehoucq, 2003). Simpser (2013) menyebutkan ada sejumlah kegiatan yang termasuk dalam kategori manipulasi pemilu, antara lain: merusak kotak suara; memfalsifikasi hasil pemilu; mempengaruhi daftar registrasi pemilih; pembelian suara sebelum pemilu; pembelian suara selama pemilu; mempersulit pendaftaran pemilih; mempersulit pendaftaran calon; mengintimidasi pemilih sebelum pemilu; mengintimidasi pemilih selama pemilu; mengintimidasi calon; menggunakan hak pilih berkali-kali; dan penggunaan hak pilih oleh orang yang tidak berhak memilih.

Simpser (2013) menyebutkan bahwa satusatunya tujuan dari manipulasi pemilu adalah kemenangan pemilu. Oleh karena itu, sebuah manipulasi pemilu dilakukan karena adanya kepentingan dari parpol, pemerintah, rezim, dan atau orang yang sedang berkuasa untuk dapat mempercepat dan memastikan kemenangan itu sendiri. Simpser (2013) menambahkan bahwa manipulasi dilakukan karena adanya efek. Efek dari manipulasi dapat langsung kepada kemenangan dalam pemilu. Efek kedua yang tidak langsung adalah pengaruh dari manipulasi pemilu pada pilihan dan tingkat laku dari berbagai macam aktor politik.

Sebab lain terjadinya manipulasi pemilu adalah kelemahan dalam regulasi pemilu. McElwain (2008: 3) menilai bahwa regulasi pemilu (electoral laws) adalah salah satu pintu masuk terjadinya manipulasi karena regulasi pemilu memiliki dampak keberpihakan (nonneutral). Manipulasi pemilu dapat berhasil memenangkan pihak tertentu melalui regulasi pemilu. Hal itu dikarenakan regulasi pemilu berdampak penting terhadap hasil pemilu (Renwick, 2010: 1).

\section{METODE}

Artikel ini ditulis dari hasil penelitian yang menggunakan metode kualitatif. Metode kualitatif dipilih karena salah satu kelebihannya yaitu menekankan pada kedalaman data dan analisis. Penelitian ini dilakukan dengan menggunakan metode pengumpulan data berupa wawancara berkelompok, depth interviews, dan studi dokumen. Informan dari penelitian ini antara lain: para anggota KPU yang diberhentikan (dilakukan dengan cara wawancara berkelompok), mantan anggota tim 
sukses salah satu calon bupati (RA), mantan tim seleksi penyelenggara pemilu ( $\mathrm{J}$ dan SE), mantan penyelenggara pemilu (ENG), mantan penyelenggara pemilu (MY), dua orang pengurus dari dua partai politik, dan dua orang tokoh masyarakat.

Data tersebut dikumpulkan selama bulan Agustus 2016. Informan ditentukan dengan cara mendasarkan pada relevansi informan dengan data yang dibutuhkan. Untuk memvalidasi data yang diperoleh, penulis melakukan proses triangulasi dengan melakukan cross-check data dan jawaban yang diperoleh dengan informan lainnya (Mertens dan Hesse-Biber, 2012; Yeasmin dan Rachman, 2012). Tujuannya adalah agar data yang penulis peroleh dapat menjadi seobjektif mungkin. Analisis data dilakukan dengan mengkategorisasi data yang relevan untuk dimasukkan di dalam artikel ini. Kategorisasi data itu kemudian dikaitkan kembali dengan teori di dalam pembahasan.

\section{HASIL DAN PEMBAHASAN}

\section{Kronologis Manipulasi Pilkada Labuhan Batu Selatan}

Pilkada Labuhan Batu Selatan dilaksanakan pada 9 Desember 2015. Pilkada tersebut diikuti oleh tiga pasangan calon, yaitu Wildan Aswan-Kholil Jufri Harahap, Usman-Arwi Winata, dan Basyaruddin Siregar-Yuspin. Berdasarkan hasil perhitungan KPU Labuhan Batu Selatan melalui pengumuman KPU Labuhan batu Selatan nomor 1289/Kpts/ KPU-Kab.002.969538/XII/2015 tertanggal 17 Desember 2015, pasangan Wildan AswanKholil Jufri Harahap meraih suara terbanyak dengan 95.729 suara atau 61,48\% (lihat Tabel 2).

Mencuatnya persoalan manipulasi dalam Pilkada Labuhan Batu Selatan 2015 berawal dari proses yang terjadi di tahapan pencalonan. Pada 15 Agustus 2015, KPU Kabupaten Labuhan Batu Selatan mengeluarkan putusan yang menyebutkan bahwa bakal calon bupati dan wakil bupati Labuhan Batu Selatan bernama Usman dan Arwi Winata tidak memenuhi syarat (TMS) sebagai calon bupati dan wakil bupati Labuhan Batu Selatan. Putusan ini tidak dapat diterima dan dianggap keliru oleh pasangan Usman-Arwi dikarenakan dua sebab. Pertama, putusan tersebut dikeluarkan oleh KPU Labuhan Batu Selatan sembilan
Tabel 2. Hasil Perhitungan Suara Pilkada Labuhan Batu Selatan Tahun 2015

\begin{tabular}{|c|c|c|c|}
\hline No. & $\begin{array}{c}\text { Nama Pasangan } \\
\text { Calon }\end{array}$ & $\begin{array}{l}\text { Perolehan } \\
\text { Suara Sah }\end{array}$ & Persentase \\
\hline 1. & $\begin{array}{l}\text { Wildan Aswan } \\
\text { Tanjungdan } \\
\text { Kholil Jufri } \\
\text { Harahap }\end{array}$ & 95.729 & $61,48 \%$ \\
\hline 2. & $\begin{array}{l}\text { UsmandanArwi } \\
\text { Winata }\end{array}$ & 59.080 & $37,95 \%$ \\
\hline 3. & $\begin{array}{l}\text { Basyaruddin } \\
\text { Siregar danY- } \\
\text { uspin }\end{array}$ & 884 & $0,57 \%$ \\
\hline & $\begin{array}{l}\text { Jumlah Suara } \\
\text { Sah Seluruh } \\
\text { Calon }\end{array}$ & 155.693 & $100 \%$ \\
\hline
\end{tabular}

Sumber: http://kpu-labuhanbatuselatankab.go.id/, Desember 2015.

hari sebelum tanggal penetapan pasangan calon. yaitu 24 Agustus 2015. Kedua, hal itu bertentangan dengan PKPU Nomor 2 Tahun 2015 tentang Program, Tahapan, dan Jadwal sehingga teradu dinilai melanggar kode etik Pasal 5 huruf i Peraturan Bersama KPU, Bawaslu, dan DKPP Nomor 13.11.1 Tahun 2012 tentang Kode Etik Penyelenggara Pemilu (wawancara dengan RA, 4 Agustus 2016).

Sebelum KPU Labuhan Batu Selatan mengeluarkan keputusan yang menyatakan pasangan Usman dan Arwi tidak memenuhi syarat sebagai calon, sudah ada kejanggalan dalam proses tahapan pemilukada di Labuhan Batu Selatan, yaitu ketika pada tanggal 28 Juli 2015, pasangan Usman dan Arwi Winata menyerahkan Formulir Model B sampai dengan Formulir Model B.4. KWK Parpol. Pasangan yang diusung oleh 3 Partai Politik yakni Gerindra, PDI-P dan Golkar, ditolak berkasnya oleh KPU Labuhan Batu Selatan dengan alasan PDI-P telah mendaftarkan terlebih dahulu pasangan yang lain (wawancara dengan RA, 4 Agustus 2016).

Para penyelenggara Pilkada Labuhan Batu Selatan yang diberhentikan tidak sependapat dengan RA. Menurut mereka, mereka belum pernah mengeluarkan satu keputusan, namun sudah diklaim bahwa mereka telah mengeluarkan satu keputusan. Pada saat masa penetapan calon, mereka diberi sanksi oleh KPU Provinsi Sumatera Utara tidak boleh membuat keputusan selama satu hari (Wawancara berkelompok, 3 Agustus 2016). Meskipun begitu, informan lain, SR, mengatakan bahwa 
KPU Labuhan Batu Selatan memang telah mengeluarkan keputusan Tidak Memenuhi Syarat sebelum waktu seharusnya. Penetapan itu juga terjadi sebelum adanya rapat pleno penetapan calon (wawancara pada 4 Agustus 2016).

Terkait penolakan terhadap dukungan PDIP kepada pasangan UMAR, menurut pihak KPU Labuhan Batu Selatan, alasan penolakan berkas dukungan PDI-P karena sebelumnya pada tanggal 26 Juli 2015 mereka telah menerima pendaftaran pasangan Calon Bupati dan Calon Wakil Bupati atas nama Wildan Aswan Tanjung dan Kholil Jufri Harahap yang didukung juga oleh PDI-P. Pasangan WildanKholil didukung oleh PDI-P sejak tanggal 25 Juli 2015, dan surat dukungan tersebut dijadikan lampiran berkas pendaftaran pasangan WildanKholil pada tanggal 26 Juli 2015 (Wawancara berkelompok dengan mantan penyelenggara pemilu, 3 Agustus 2016).

Dalam perkembangannya kemudian, Ketua PDIP Labuhan Batu Selatan, Zainal Harahap dipecat oleh DPP PDI-P. DPP PDIP kemudian mengeluarkan surat dukungan kepada pasangan Usman-Arwi (UMAR). Sedangkan, dukungan dari Partai Golkar untuk pasangan UMAR tidak dipermasalahkan. Untuk dukungan dari Partai Golkar, KPU tidak menolak karena pasangan UMAR sudah mendapatkan surat dukungan dari kedua kubu di Partai Golkar, yaitu kubu Agung Laksono dan kubu Aburizal Bakri. Namun, anehnya pada saat pasangan Wildan-Kholil mendaftar dengan surat dukungan di antaranya dari Partai Golkar, KPU tidak menolak, padahal surat dukungan dari Partai Golkar hanya datang dari kubu Agung Laksono dan tidak melampirkan surat dukungan dari kubu Aburizal Bakri.

Sikap KPU Labuhan Batu Selatan yang menolak berkas pendaftaran tersebut di atas disayangkan pihak pasangan UMAR. KPU Labuhan Batu Selatan sebetulnya tidak perlu mencoret pasangan UMAR karena sebenarnya ada tahapan yang disediakan dalam Pilkada, yaitu verifikasi. Sampai dengan tanggal 28 Juli 2015 KPU Labuhan Batu Selatan semestinya menerima semua pendaftaran yang masuk. Setelah itu, baru mengecek berkas-berkas yang ada dalam bentuk proses verifikasi dokumen atau berkas (wawancara dengan RA, 4 Agustus 2016).

Pihak pasangan UMAR juga menyayangkan sikap Panwas Labuhan Batu Selatan yang saat pendaftaran tersebut hadir sebagai saksi. Pasalnya, saat itu Panitia Pengawas (Panwas) Labuhan Batu Selatan hadir dalam terjadinya proses penolakan. Panwas Labuhan Batu Selatan semestinya mengeluarkan kebijakan dan mengingatkan KPU Labuhan Batu Selatan agar menerima berkas dan melakukan verifikasi setelah itu. Ketika melihat terdapat persoalan, semestinya Panwas membuat rekomendasi yang kemudian harus ditindaklanjuti oleh KPU Labuhan Batu Selatan (wawancara dengan RA, 4 Agustus 2016).

Atas peristiwa penolakan pendaftaran oleh KPU Labuhan Batu Selatan tersebut, Panwas Labuhan Batu Selatan akhirnya berusaha melakukan klarifikasi. Pada tanggal 10 Agustus 2015, pasangan UMAR mendapat undangan dari Panwas Labuhan Batu Selatan untuk memberikan keterangan klarifikasi sebagai saksi perihal penolakan dukungan DPC PDIP kepada pasangan UMAR. Sebelumnya, pada tanggal 3 Agustus 2015, Panwas Labuhan Batu Selatan juga sudah melakukan klarifikasi ke DPP PDIP yang hasilnya adalah bahwa dukungan PDIP untuk pasangan UMAR.

Setelah pada tanggal 15 Agustus 2015 KPU Labuhan Batu Selatan menyebutkan bahwa pasangan UMAR tidak memenuhi syarat sebagai calon, pasangan UMAR kemudian melaporkan kasusnya ke KPU Provinsi Sumatera Utara. Proses klarifikasi dilakukan terhadap pihak-pihak terkait. Rujukan yang digunakan oleh KPU Provinsi Sumatera Utara adalah berdasarkan PKPU Nomor 25 Tahun 2013 jo. PKPU Nomor 13 Tahun 2014.

Pada tanggal 19 Agustus 2015 kesimpulan yang diambil KPU Provinsi Sumatera Utara dituangkan dalam Formulir PAP-1 tentang Hasil Klarifikasi Dugaan Pelanggaran Administrasi Pemilu. Pasangan UMAR menyampaikan bahwa dukungan PDIP terhadap pasangan Wildan-Kholil telah dicabut oleh DPP PDIP dan mengalihkannya kepada pasangan UMAR melalui surat DPP PDIP nomor: 171/EX/ DPP/V11/2015 tertanggal 26 Juli 2015 yang ditujukan kepada KPU Kabupaten Labuhan Batu Selatan. Berdasarkan hasil klarifikasi yang telah dilakukan, KPU Provinsi Sumatera Utara kemudian mengeluarkan Keputusan Nomor: 1638/Kpts/KPU-Prov-002/VIII/2015 tentang Pemberhentian/Tidak Melibatkan Anggota KPU Kabupaten Labuhan Batu Selatan Dalam 
Kegiatan Tahapan Penetapan Pasangan Calon Bupati dan Wakil Bupati Kabupaten Labuhan Batu Selatan Provinsi Sumatera Utara.

Klarifikasi yang dilakukan KPU Provinsi Sumatera Utara ditandai dengan dikeluarkannya Berita Acara Nomor: 1617/BA/VIII/2015 tanggal 19 Agustus 2015 tentang Hasil Klarifikasi Dugaan Pelanggaran Administrasi Pemilu yang dilakukan oleh KPU Kabupaten Labuhan Batu Selatan dalam Pemilihan Bupati dan Wakil Bupati Labuhan Batu Selatan Tahun 2015. Setelah itu, pada tanggal yang sama, dikeluarkanlah Keputusan Dugaan Pelanggaran Administrasi Pemilu (PAP-2B) KPU Kabupaten Labuhan Batu Selatan Nomor: 07/KPU-Prov-002/PAP/VIII/2015.

Dengan dikeluarkannya Keputusan KPU Provinsi Nomor 1638, KPU Provinsi Sumatera Utara berarti telah mengambil alih tugas KPU Kabupaten Labuhan Batu Selatan dalam kegiatan Penetapan pasangan Calon Bupati dan Wakil Bupati Labuhan Batu Selatan. Adapun jadwal yang sudah ditentukan untuk penetapan pasangan calon adalah tanggal 24 Agustus 2015. Pengambilalihan tugas Penetapan Pasangan Calon oleh KPU Provinsi ini hanya untuk 1 (satu) hari itu saja, yaitu tanggal 24 Agustus 2015 yang dalam Tahapan Pemilihan Bupati dan Wakil Bupati Labuhan Batu Selatan jatuh pada tanggal tersebut. Setelah tanggal tersebut, Tahapan Pemilihan selanjutnya diserahkan kembali kepada pihak KPU Labuhan Batu Selatan.

Pada tanggal itulah KPU Provinsi Sumatera Utara kemudian mengeluarkan putusan hasil rapat pleno yang termaktub dalam Keputusan KPU Provinsi Sumatera Utara Nomor 1661/kpts/KPUProv-002/VIII/2015 mengenai Penetapan Pasangan Calon Bupati dan Wakil Bupati Kabupaten Labuhan Batu Selatan Provinsi Sumatera Utara Tahun 2015. Penetapan Pasangan Calon Bupati dan Wakil Bupati Kabupaten Labuhan Batu Selatan oleh KPU Provinsi Sumatera Utara tersebut bagi Pasangan Calon Usman Harun, SE, M,Si dan Arwi Winata adalah tanpa mengikutsertakan PDIP (Keputusan DKPP Nomor 70/DKPPPKE-IV/2015). Dalam kutipan putusannya, disebutkan bahwa Pasangan Calon Bupati dan Wakil Bupati yang memenuhi syarat adalah: (1) Wildan Aswan Tanjung dan Kholil Jufri Harahap; (2) Basyaruddin Siregar dan Yuspin; dan (3) Usman Harun dan Arwi Winata.
Adapun alasan yang dikemukakan KPU Provinsi Sumatera Utara ketika mengambil alih Tahapan Penetapan Calon tersebut adalah seperti disebutkan dalam Putusan DKPP tentang kasus tersebut sebagai berikut:

1. Bahwa KPU Provinsi Sumatera Utara Mengambil Alih Tugas Teradu (KPU Kabupaten Labuhan Batu Selatan.) dalam Penetapan Pasangan Calon Tanggal 24 Agustus 2015 adalah Menyelamatkan dan Menjamin Hak Konstitusi dari Pasangan Calon H. Usman, SE, MSi dan Arwi Winata untuk Calon Bupati Dan Wakil Bupati 2015;

2. Bahwa apabila tidak diambil alih KPU Provinsi Sumatera Utara dalam Penetapan Pasangan Calon Tanggal 24 Agustus 2015 maka Pasangan Calon H. Usman, SE, MSi dan Arwi Winata dipastikan TMS (Tidak Memenuhi Syarat), karena sebelum Tanggal 24 Agustus 2015 sudah ada Keputusan Teradu (KPU Kabupaten Labuhan Batu Selatan) yang disampaikan kepada Pasangan Calon H. Usman, SE, MSi dan Arwi Winata.

Setelah dikeluarkannya Keputusan tentang Penetapan Pasangan Calon, selanjutnya pada tanggal 26 Agustus 2015 dilakukan tahapan Pengundian Nomor Urut. Acara ini diadakan oleh KPU Labuhan Batu Selatan, berlangsung di Convention Hall Hotel Grand Suma Blok Songo Kotapinang, Labuhan Batu Selatan. Kegiatan ini dilakukan oleh KPU Labuhan batu Selatan karena telah diberikannya kembali kewenangan oleh KPU Provinsi Sumatera Utara untuk melaksanakan tahapan pemilihan selanjutnya (wawancara dengan ENG, 2 Agustus 2016).

Sementara itu, KPU Labuhan Batu Selatan bereaksi atas Keputusan KPU Provinsi yang telah mengambil alih tugas dalam kegiatan Penetapan pasangan Calon Bupati dan Wakil Bupati Labuhan Batu Selatan. Mereka mempertanyakan tindakan KPU Provinsi Sumatera Utara mengambil alih tugas mereka dan hal itu dianggap menyalahi tugas dan kewenanganKPUProvinsiSumateraUtara.KPU Labuhan Batu Selatan kemudian mengirim surat kepada Mahkamah Konstitusi (MK). Surat yang ditandatangani oleh 4 (empat) Komisioner itu (minus Ependi Pasaribu) meminta mengajukan permohonan Nomor 1/SKLN-XI11/2015 
perihal Pengujian Sengketa Kewenangan Lembaga Negara dengan Pemohon KPU Labuhan Batu Selatan dan Termohon KPU Provinsi Sumatera Utara. Walaupun KPU Labuhan Batu Selatan akhirnya mengajukan permohonan penarikan kembali surat pengajuan permohonan sengketa kewenangan lembaga Negara, Mahkamah Konstitusi dalam amar putusannya menyampaikan bahwa apa yang dimohonkan adalah permasalahan internal KPU dan harus diselesaikan oleh KPU sendiri (antara KPU Provinsi Sumatera Utara dengan KPU Labuhan Batu Selatan) (Wawancara berkelompok dengan mantan penyelenggara pemilu, 3 Agustus 2016).

Setelah KPU Provinsi Sumatera Utara sudah menetapkan Pasangan Calon, Panwas Labuhan Batu Selatan kemudian melakukan upaya klarifikasi kembali. Pada tanggal 26 Agustus 2015, di hari pengundian nomor pasangan calon, Panwas Labuhan Batu Selatan mengambil keputusan memerintahkan KPU Labuhan Batu Selatan agar melakukan klarifikasi keabsahan Dokumen Rekomendasi DPP PDIP ke kantor DPP PDIP di Jakarta. Keputusan Panwas Labuhan Batu Selatan dituangkan dalam Surat Keputusan Sengketa dengan Nomor Permohonan: 001/PS/PWSL. LBS.02.31/VIII/2015, tanggal 27 Agustus 2015, yang menetapkan:

a. Mengabulkan Permohonan Pemohon untuk sebagian;

b. Memerintahkan kepada KPU Labuhan Batu Selatan agar melakukan Klarifikasi keabsahan dokumen rekomendasi DPP PDIP di Jakarta dan hasil Klarifikasi keabsahan dokumen tersebut dijadikan dasar oleh Termohon untuk menentukan persyaratan dukungan pencalonan yang diusung oleh PDIP;

c. Meminta kepada KPU Labuhan Batu Selatan untuk melaksanakan Keputusan ini.

Hasil klarifikasi keabsahan dokumen tersebut akan dijadikan dasar oleh pasangan UMAR untuk menentukan persyaratan dukungan yang diusung PDI Perjuangan. Untuk keperluan itu, Panwas Labuhan Batu Selatan dalam Persidangan Sengketa telah memanggil dan memeriksa sejumlah pihak, seperti Usman dan anggota tim suksesnya, beserta pengurus PDIP Labuhan Batu
Selatan (Wawancara dengan MY, 3 Agustus 2016).

Dalam rangka melaksanakan Perintah Panwas Labuhan Batu Selatan, pada 4 September 2015 KPU Labuhan Batu Selatan melakukan klarifikasi ke DPP PDIP. Hasilnya adalah bahwa "dukungan PDI Perjuangan untuk pasangan calon Usman dan Arwi Winata, sesuai model B.1 KWK Parpol". DPP PDIP telah mengeluarkan Surat DPP PDIP Nomor 678/IN/DPP/VII/2015 tentang Pencabutan sekaligus Penetapan Rekomendasi, dan Surat DPP PDIP Nomor 171 / EX/DPP/VTI/2015 tentang Pencabutan Model B.1- KWK PARPOL atas nama Wildan Aswan Tanjung dan Kholil Jufri Harahap serta Penetapan Rekomendasi.Hasil klarifikasi tersebut berarti sama dengan hasil klarifikasi Panwas Labuhan Batu Selatan pada tanggal 3 Agustus 2015.

Akan tetapi, sekalipun sudah mendapatkan jawaban secara jelas dari DPP PDIP, dan jawaban tersebut sesuai dengan hasil klarifikasi Panwas Labuhan Batu Selatan, KPU Labuhan Batu Selatan tetap saja tidak memasukkan dan menetapkan dukungan PDI Perjuangan kepada pasangan UMAR. Dalam surat yang dikirim kepada Panwas Labuhan Batu Selatan nomor 894/KPU- Kab.002.969538/IX/2015 tertanggal 14 September 2015, KPU Labuhan Batu Selatan mengatakan melakukan pengkajian sehingga mereka memutuskan tidak dapat mencoret PDIP sebagai Partai Pengusung Pasangan Calon Bupati dan Wakil Bupati atas nama Wildan Aswan Tanjung dan Kholil Jufri Harahap.

Dikeluarkannya surat nomor 894 di atas bertentangan dengan ketentuan pasal 144 Undang-Undang Nomor 8 Tahun 2015, di mana KPU Labuhan Batu Selatan seharusnya wajib melaksanakan/menindaklanjuti Putusan Panwas Labuhan Batu Selatan dengan menetapkan dukungan PDIP kepada pasangan UMAR (Putusan DKPP dan pasal 144 dalam Undang-Undang Nomor 8 tahun 2015 Tentang Perubahan Atas Undang-Undang Nomor 1 Tahun 2015 Tentang Penetapan Peraturan Pemerintah Pengganti Undang-Undang Nomor 1 Tahun 2014 Tentang Pemilihan Gubernur, Bupati, dan Walikota Menjadi Undang-Undang) (wawancara dengan ENG, 2 Agustus 2016).

Atas tindakan tersebut dapat diartikan bahwa KPU Labuhan Batu Selatan telah melakukan pelanggaran terhadap pasal 144 Undang-Undang Nomor 8 tahun 2015. Selain itu, tindakan KPU Labuhan Batu Selatan 
yang tidak menetapkan dukungan PDIP kepada pasangan UMAR, padahal sudah ada keputusan dan perintah dari Panwas Labuhan Batu Selatan, merupakan pelanggaran terhadap pasal 150 Undang-Undang Nomor 8 Tahun 2015. Pasal 150 tersebut berbunyi:

(1) Putusan pengadilan terhadap kasus tindak pidana Pemilihan yang menurut UndangUndang ini dapat mempengaruhi perolehan suara peserta Pemilihan harus sudah selesai paling lama 5 (lima) hari sebelum KPU Provinsi dan/atau KPU Kabupaten/ Kota menetapkan hasil Pemilihan.

(2) KPU Provinsi dan/atau KPU Kabupaten/ Kota wajib menindaklanjuti putusan pengadilan sebagaimana dimaksud pada ayat (1).

Tindakan KPU Labuhan Batu Selatan tersebut adalah Pelanggaran Kode Etik Terhadap Pasal 11 huruf a,b,c, dan d Peraturan Bersama KPU, Bawaslu dan DKPP Nomor 13.11.1 Tahun 2012 Tentang Kode Etik Penyelenggara Pemilu (Putusan DKPP).

Sementara itu, sekalipun pada tanggal 24 Agustus 2015 KPU Provinsi Sumatera Utara sudah menetapkan pasangan calon (Keputusan KPU Nomor $1661 \mathrm{Op}$ Cit), kasus penetapan pasangan calon di Kabupaten Labuhan Batu Selatan ternyata belum berakhir. Pada tanggal 10 September 2015, KPU Labuhan Batu Selatan memberikan konferensi pers melalui harian "Medan Bisnis", yang menyatakan bahwa KPU Labuhan Batu Selatan pastikan dukungan PDIP untuk Pasangan Wildan-Kholil. Atas tindakan KPU Labuhan Batu Selatan tersebut, pada tanggal 18 September 2015, pasangan UMAR menyurati KPU Provinsi Sumatera Utara dengan tembusan kepada KPU Kabupaten Labuhan Batu Selatan. Mereka meminta KPU Provinsi Sumatera Utara memberikan kepastian hukum atas hasil klarifikasi ke DPP PDIP.KPU Labuhan Batu Selatan membalas dengan surat kepada pasangan UMAR bahwa keputusan memasukkan PDIP berada di Kewenangan KPU Provinsi Sumatera Utara.

KPU Provinsi Sumatera Utara menyurati Pasangan UMAR bahwa dukungan PDIP sudah ditindaklanjuti dengan menanyakannya kepada pihak KPU Labuhan Batu Selatan, namun yang bersangkutan tidak memberikan jawaban yang menjelaskan Kepastian Hukum seperti diminta pihak UMAR. Tindakan tersebut adalah Pelanggaran Kode Etik sebagai Penyelenggara Pemilukada.Tindakan tersebut adalah Pelanggaran Kode Etik dengan Tidak Memberikan Kepastian Hukum, Tidak Bekerja Profesional, Jujur, Adil Dan Netral sesuai pasal 5 Peraturan bersama KPU, Bawaslu dan DKPP Nomor 13.11.1 tahun 2012 Tentang Kode Etik Penyelenggara Pemilu (Putusan DKPP).

Kasus Pemilukada di Labuhan Batu Selatan terus berlanjut seiring berjalannya tahapan pemilukada, yaitu tahapan pemasangan Alat Peraga Kampanye (APK) oleh KPU Labuhan Batu Selatan. Pada tanggal 21 September 2015, KPU Labuhan Batu Selatan memasang APK dan Bahan Kampanye yang memasukkan dukungan PDI Perjuangan kepada pasangan Wildan-Kholil. Dalam APK dan Bahan Kampanye tersebut, pasangan UMAR hanya di dukung 2 (dua) Partai Politik yaitu Partai Gerindra dan Partai Golkar, sementara PDIP dicoret dari daftar Partai Pendukung Pasangan Calon tersebut (wawancara dengan RA, 4 Agustus 2016).

Tindakan KPU Labuhan Batu Selatan dianggap melakukan Pelanggaran Pasal 29 PKPU Nomor 7 Tahun 2015 Tentang Kampanye Pemilihan Gubernur dan Wakil Gubernur, Bupati dan Wakil Bupati dan/atau Walikota dan Wakil Walikota (Putusan DKPP). Tindakan yang dilakukan KPU Labuhanbatu Selatan lagi-lagi memicu protes pasangan UMAR. Mereka merasa dirugikan dengan tindakan tersebut. Mereka menuduh bahwa tindakan KPU Labuhan Batu Selatan merupakan wujud keberpihakan KPU kepada Pasangan WildanKholil. Apalagi hal itu bertentangan dengan Keputusan Panwas Labuhan Batu Selatan dan Hasil Klarifikasi KPU Labuhan Batu Selatan ke DPP PDIP pada tanggal 4 September 2015 (wawancara dengan RA, 4 Agustus 2016).

Pada tanggal 1 Oktober 2015, KPU Labuhan Batu Selatan mengeluarkan Keputusan KPU bahwa "dukungan yang sah PDI Perjuangan adalah kepada Pasangan WildanKholil". Keputusan KPU Labuhan Batu Selatan tersebut disampaikan melalui surat Nomor 964/KPU-Kab.002969538/X/2015, kepada Pasangan UMAR Surat tersebut juga ditembuskan ke Panwas Labuhan Batu Selatan.Keputusan final KPU Labuhan Batu Selatan itu tentunya lagi-lagi bertentangan dengan Hasil Klarifikasi KPU Kabupaten Labuhan Batu Selatan ke DPP PDIP, pada tanggal 4 September 2015. 
Atas berbagai tindakan dan keputusan yang dikeluarkan oleh KPU Labuhan Batu Selatan, juga sudah adanya keputusan yang dikeluarkan oleh Panwaslu Labuhan Batu Selatan, pasangan UMAR kemudian melayangkan surat pengaduan kepada Dewan Kehormatan Penyelenggara Pemilihan Umum Republik Indonesia (DKPP RI). Pengaduan tersebut tercatat sebagai pengaduan nomor 115/I-P/L-DKPP/2015 tanggal 7 September 2015, yang diregistrasi dengan Perkara Nomor 76/DKPP-PKE-IV/2015. Setelah melakukan persidangan, dalam amar putusannya, DKPP RI menjatuhkan Putusan dugaan pelanggaran Kode Etik Penyelenggara Pemilu yang dilakukan oleh KPU Kabupaten Labuhan Batu Selatan, dengan menjatuhkan sanksi berupa Pemberhentian Tetap kepada 4 (empat) orang Komisioner KPU tersebut. Keempatnya adalah atas nama Imran Husaini Siregar, selaku Ketua merangkap Anggota KPU Kabupaten Labuhan Batu Selatan, Irwansyah, Khairul Mubarrik Harahap, dan Salim selaku Anggota KPU Kabupaten Labuhan Batu Selatan. DKPP RI juga menjatuhkan sanksi berupa Peringatan Keras kepada Komisioner KPU atas nama Ependi Pasaribu selaku Anggota KPU Kabupaten Labuhan Batu Selatan.

Dalam Sidang DKPP RI tersebut, bertindak sebagai Pengadu adalah Usman dan Arwi Winata. Sedangkan Teradu adalah 5 (lima) orang Komisioner KPU Labuhan Batu Selatan. Sidang DKPP RI dipimpin langsung oleh Jimly Asshiddiqieselaku Ketua merangkap Anggota, Anna Erliyana, Valina Singka Subekti, Saut Hamonangan Sirait, Nur Hidayat Sardini, Endang Wihdatiningtyas, dan Ida Budhiati masing-masing sebagai Anggota.

Keputusan DKPP RI yang dikeluarkan pada hari Jumat, 13 November 2015 tersebut mengakhiri konflik yang terjadi dalam proses tahapan Pilkada Labuhan Batu Selatan, hususnya bagian tentang proses penetapan pasangan calon. Para Komisioner KPU Labuhan Batu Selatan yang diberhentikan, sebanyak empat orang, kemudian diganti. Penggantinya adalah empat orang nomor urut berikutnya yang lolos dalam seleksi calon anggota KPU Labuhan Batu Selatan yang telah ditetapkan oleh Tim Seleksi KPU Labuhan Batu Selatan.

Dari uraian tentang proses tahapan Pilkada di atas, khususnya bagian mengenai proses penetapan pasangan calon dalam
Pilkada Labuhan Batu Selatan 2015, penulis berpendapat bahwa tindakan-tindakan dalam Pilkada Labuhan Batu Selatan 2015 mengindikasikan terjadinya manipulasi pemilu. Pertama, meskipun tindakan-tindakan yang terjadi dalam Pilkada Labuhan Batu Selatan tidak ditujukan untuk mengeksekusi kontrol terhadap sistem pemilu, namun terdapat tindakan yang mengeksekusi kontrol terhadap hasil dan maknanya, khususnya terlihat dalam proses penetapan pasangan calon dan partai politik pendukungnya. Setidaknya terdapat tiga penjelasan terkait hal tersebut. Penjelasan pertama yaitu eksekusi kontrol terhadap hasil dan maknanya terlihat dari tindakan KPU Labuhan Batu Selatan menolak pendaftaran dan menyatakan Tidak Memenuhi Syarat (TMS) terhadap Pasangan UMAR, padahal bakal pasangan calon tersebut mengantongi surat dukungan DPP PDI-Perjuangan yang sah. Di samping itu, eksekusi kontrol terhadap hasil juga dapat dilihat dalam tindakan KPU Labuhan Batu Selatan tidak melaksanakan dan mentaati keputusan KPU Provinsi Sumatera Utara Nomor 1661/kpts/KPUProv-002/VIII/2015, yang telah menetapkan Pasangan Calon Bupati Bupati dan Wakil Bupati Kabupaten Labuhan Batu Selatan Provinsi Sumatera Utara Tahun 2015.

Penjelasan kedua yakni meskipun sulit membuktikan aspek keterencanaannya, namun penulis menemukan unsur massif dalam tindakan dan dampak yang terjadi dalam Pilkada Labuhan Batu Selatan. Unsur massif pertama terdapat dalam tindakan KPU Kabupaten Labuhan Batu Selatan memberikan Keputusan Hasil Verifikasi yang dilakukannya sebelum jadwal yang telah ditetapkan. Unsur massif kedua dapat dilihat dalam tindakan KPU Labuhan Batu Selatan yang mengirim surat kepada Mahkamah Konstitusi (MK) yang memohon dilakukannya pengujian sengketa kewenangan lembaga Negara, walaupun KPU Labuhan Batu Selatan akhirnya mengajukan permohonan penarikan kembali surat pengajuan permohonan tersebut. Tindakan tersebut, menurut DKPP RI membuktikan bahwa mereka tidak tunduk dan patuh pada KPU Provinsi Sumatera Utara sebagai atasannya dan berbahaya bagi penyelenggara pemilu. Artinya, setidaknya dari dua tindakan tersebut dampak massifnya terdapat pada tidak profesionalnya penyelenggara Pilkada dan kegaduhan yang 
muncul setelah pengajuan uji sengketa kewenangan lembaga negara.

Penjelasan ketiga adalah tindakantindakan dalam Pilkada Labuhan Batu Selatan terlihat berpotensi mempengaruhi hasil pemilu. Tindakan dimaksud adalah kegiatan mempersulit pendaftaran calon. Kegiatan mempersulit pendaftaran calon terlihat pada saat KPU Labuhan Batu Selatan tidak menjadikan hasil verifikasi keabsahan dokumen surat dukungan kepada PDIP sebagai rujukan untuk menetapkan dukungan, namun justru mengkajinya kembali sampai akhirnya menyatakan Tidak Memenuhi Syarat kepada pasangan UMAR. KPU Labuhan Batu Selatan juga tidak menjalankan Keputusan Panwas Labuhan Batu Selatan. Selain itu, KPU Labuhan Batu Selatan juga memberikan pernyataan di media massa sebelum penetapan resmi pasangan calon dan menyatakan bahwa dukungan DPP PDIP bukanlah untuk pasangan UMAR. Hal itu masih ditambah lagi dengan tindakan KPU Labuhan Batu Selatan mencetak Alat Peraga Kampanye (APK) tanpa berkoordinasi dengan pihak Pasangan UMAR dantidakmemasukkanPDIP sebagai pendukung pasangan UMAR, sehingga Pasangan UMAR merasa dirugikan.

\section{Analisis Sebab Terjadinya Manipulasi Pilkada Labuhan Batu Selatan 2015}

Simpser (2013) menyebutkan bahwa manipulasi pemilu dilakukan karena adanya kepentingan. Simpser juga menyebutkan manipulasi pemilu dilakukan karena adanya efek di mana manipulasi dapat langsung kepada kemenangan dalam pemilu. Hal itu yang penulis lihat terjadi dan menjadi sebab pertama terjadinya manipulasi dalam Pilkada Labuhan Batu Selatan. Kepentingan yang ada dalam kasus Pilkada Labuhan Batu Selatan adalah kepentingan untuk memastikan kemenangan petahana dalam Pilkada. Kemenangan itu dapat dengan mudah dipastikan dan dipercepat jika bupati petahana hanya menjadi "calon tunggal" dengan didampingi oleh pasangan calon "boneka" di Pilkada Labuhan Batu Selatan. Usaha menggagalkan pasangan UMAR menjadi calon bupati adalah langkah untuk mensukseskan tujuan tersebut.

Tindakan-tindakan dalam tahapan pencalonan yang dikaitkan dengan KPU Labuhan Batu Selatan seperti diutarakan di atas tak cukup dilihat sebagai sekedar tindakan tanpa tujuan.
Lebih dari itu, tindakan-tindakan itu berkaitan dengan kepentingan petahana. Seorang informan, ZH, menyebutkan bahwa indikasi keberpihakan terhadap kepentingan petahana ada dalam Pilkada Labuhan Batu Selatan 2015 (wawancara pada 5 Agustus 2016). Hal senada diutarakan oleh SR yang menyebutkan ada pihak yang memiliki kekuatan memiliki skenario dan ikut mengitervensi kebijakan KPU Labuhan Batu Selatan (wawancara pada 4 Agustus 2016). MY, informan lainnya, berpendapat bahwa indikasi upaya mempengaruhi KPU Labuhan Batu Selatan sangat kuat yang mana hal itu disebabkan oleh adaya kepentingan petahana (wawancara pada 3 Agustus 2016).

Meskipun demikian, adanya kepentingan petahana dan tindakan-tindakan manipulasi yang berkaitan dengan KPU Labuhan Batu Selatan dibantah oleh para penyelenggara Pilkada Labuhan Batu Selatan yang diberhentikan. Mereka berpendapat bahwa banyak orang yang mengatakan kalau mereka berpihak ke salah satu calon, namun mereka sendiri tidak tahu berpihaknya di mana. Jika Pemerintah Kabupaten Labuhan Batu Selatan cepat mencairkan anggaran Pilkada dan juga memberikan fasilitas yang cukup memadai untuk pelaksanaan Pilkada, maka kedua tindakan itu merupakan hal yang lumrah saja, bukan hal yang aneh. Ditambahkan oleh sekelompok informan tersebut, bahwa jika setelah diberhentikan oleh DKPP mereka menjadi pelatih saksi dari salah satu calon, bukan sebuah masalah. Hal itu dikarenakan status mereka mereka sudah tidak lagi menjadi penyelenggara Pilkada(wawancara berkelompok 3 Agustus 2016). Namun demikian, bantahan tersebut di atas dipatahkan oleh informan lain yang menyebutkan bahwa ada upaya mencegah lolosnya proses pasangan UMAR. Hal tersebut ditandai oleh berhasilnya petahana menggalang dukungan dari hampir seluruh partai politik di Labuhan Batu Selatan. Bila PDIP dan Partai Golkar juga berhasil diajak menjadi bagian dari koalisi, maka tidak ada pasangan lain selain petahanan dan calon "boneka" guna mencegah terjadinya calon tunggal (wawancara dengan RA, 4 Agustus 2016).

Adanya kepentingan petahana juga dapat dilihat dari adanya pasangan calon independen, Basyaruddin Siregar dan Yuspin yang menjadi calon, namun akhirnya pasangan itu hanya 
memperoleh suara sangat kecil, yakni 884 suara $(0,57 \%)$ dari 155.693 pemilih. Kecilnya perolehan suara pasangan itu disebut oleh informan berkaitan dengan status sebenarnya dari pasangan tersebut yang sebenarnya hanya pasangan "boneka" saja. Bekerjanya kepentingan dalam proses di Pilkada Labuhan Batu Selatan 2015 sesuai dengan skenario yaitu ketika rencana membuat semua partai politik berhasil, agar tidak menjadi satu-satunya calon, maka dimunculkanlah pasangan calon "boneka" (wawancara dengan RA, 4 Agustus 2016). Informan lain senada dengan RA. Pasangan calon independen berkampanye untuk petahana. Pasangan calon tersebut turun ke banyak tempat bukan untuk mengkampanyekan diri mereka sendiri namun justru untuk petahana. Jadi, pasangan calon independen itu ada dengan harapan dapat mendampingi petahana ketika tidak ada calon lain lagi yang bisa maju (wawancara dengan SR, 4 Agustus 2016). Apa yang disampaikan dua informan sebelumnya, dibenarkan oleh informan lain yang mengatakan hal yang senada. Ditambahkan oleh MH bahwa pasangan calon independen bukan tokoh yang dikenal di Labuhan Batu Selatan sehingga tidak mungkin dapat bersaing (wawancara dengan MH, 4 Agustus 2016).

Kepentingan petahana juga tak dapat dilepaskan dari sosok pasangan UMAR. Meskipun kalah oleh petahana, pasangan UMAR meraih suara yang tidak sedikit, yakni 37, 9\%. Masuknya berkas pendaftaran dari Bakal Pasangan Calon Usman-Arwi dianggap sebagai ancaman bagi petahana. Pasangan Calon tersebut dianggap sebagai lawan politik yang bisa menggagalkan upaya petahana menjadi Bupati kembali. Pasangan tersebut, khususnya sosok Arwi Winata, dikenal sebagai orang yang cukup merakyat dan dekat dengan masyarakat. Sekalipun beliau berasal dari keturunan etnis Tionghoa dan beragama Kristen, pengusaha yang memiliki perkebunan kelapa sawit ini dikenal sebagai seorang dermawan, ramah dan sering menolong orang. Telah banyak pula orang yang diberangkatkan ke tanah suci mekah untuk berhaji ataupun umroh. Hal itu diakui oleh MH (wawancara 4 Agustus 2016). Sifat royal sosok Arwi Winata kepada masyarakat diakui oleh SN. SN disebut-sebut memiliki rasa sosial yang tinggi (wawancara 3 Agustus 2016). Pasangan UMAR dinilai sebagai pemimpin alternatif sehingga petahana merasa perlu melakukan antisipasi (wawancara dengan MY, 3 Agustus 2016). Antisipasi itu yang kemudian terwujud dalam terjadi permasalahan dalam tahapan pencalonan seperti diuraikan di atas (wawancara dengan RA, 4 Agustus 2016).

Kepentingan petahana juga dapat dilihat sejak tahapan awal Pilkada, yaitu saat Tim Seleksi anggota KPU Labuhan Batu Selatan bekerja. Tim Seleksi bertanggung jawab melakukan rekrutmen anggota KPU Labuhan Batu Selatan. Tim Seleksi terdiri dari lima orang dan kesemuanya berasal dari kalangan akademisi. Tim ini mendapatkan pembekalan dari KPU Provinsi Sumatera Utara di Garuda Plaza Hotel Medan pada tanggal 4 Agustus 2013.Menurut SR, rekrutmen KPU Labuhan Batu Selatan bermasalah karena orang partai berpeluang untuk menempatkan "orang"nya di lembaga itu. Adanya titipan itu yang kemudian mempengaruhi kebijakan lembaga itu (wawancara 4 Agustus 2016). Namun, informan lain mengatakan yang berbeda. Bupati petahana menurut salah seorang informan tidak pernah mendesain dan melakukan intervensi terhadap proses seleksi anggota KPU Labuhan Batu Selatan (wawancara dengan SN 3 Agustus 2016). Meskipun demikian, informan lain tidak sependapat dengan SN. Menurutnya, ketika KPU Labuhan Batu Selatan berani mengambil resiko (dipecat), artinya ada tekanan dana tau iming-iming dari pihak lain (wawancara dengan MY, 3 Agustus 2016). Ditambahkan oleh SE sebagai anggota Timsel, ada upaya campur tangan terhadap pekerjaan Timsel dari orang yang diduga merupakan utusan petahana (wawancara 2 Agustus 2016). Anggota Timsel lainnya, J, membenarkan ada yang mengatasnamakan diri sebagai utusan pihak petahana saat itu (wawancara 5 Agustus 2016). Tak hanya menghubungi Timsel, pihak yang disebut di atas juga mencoba menyuap Timsel dengan menawarkan sejumlah dana dengan harapan hasil seleksi bisa dipengaruhi agar meloloskan calon anggota KPU Labuhan Batu Selatan tertentu. Namun kemudian seluruh Timsel menolak tawaran tersebut (wawancara dengan SE, 2 Agustus 2016). Mengenai adanya usaha mempengaruhi Timsel itu dibenarkan oleh $\mathrm{J}$ dan orang yang dimaksud tersebut mengaku sebagai wartawan. J menyebut bahwa dirinya terpaksa harus mengganti nomor telepon berkali-kali karena terus dihubungi orang yang 
berusaha mempengaruhi itu (wawancara 5 Agustus 2016).

Proses seleksi meliputi beberapa tahapan, yaitu pendaftaran dan penerimaan administrasi, seleksi administrasi, seleksi tertulis, tes kesehatan, tes psikologi, dan wawancara. Selain bermasalah karena Timsel berusaha ditawari, ketika Timsel juga terdapat kejanggalan. Salah satunya ketika distribusi ujian tertulis. Soal ujian tertulis yang dikirim oleh KPU Provinsi, hanya dikirimkan sampai Kabupaten Labuhan Batu saja, tidak sampai ke Labuhan Batu Selatan. Seharusnya soal ujian tersebut diterima langsung oleh Tim Seleksi di Kota Pinang, Labuhan Batu Selatan. Hal ini tentu riskan, karena jika soal tersebut harus dijemput oleh anggota Tim Seleksi di Labuhan Batu Selatan, dikhawatirkan ada kecurigaan bahwa dalam proses tersebut muncul tuduhan dibukanya soal ujian oleh Tim Seleksi saat dalam perjalanan. Akhirnya Tim Seleksi berhasil meminta agar soal ujian tersebut dikirim sampai ke Labuhan Batu Selatan. Dengan disaksikan berbagai pihak, segel soal kemudian dibuka, dan dilaksanakanlah proses ujian tertulis. Dari situ diduga kuat ada kemungkinan bahwa ada kebocoran soal ujian tertulis (wawancara dengan SE, 2Agustus 2016). Informan lain tidak membantah kemungkinan hal itu terjadi. Meskipun demikian, informan itu menambahkan jika itu terjadi, berarti hal itu terjadi sejak soal berangkat dari Kota Medan, bukan ketika sudah dibagikan di Labuhan Batu Selatan (wawancara dengan J, 5 Agustus 2016).

Sebab kedua yang mendukung terjadinya manipulasi dalam Pilkada Labuhan Batu Selatan 2015 adalah karena adanya kelemahan dalam regulasi pemilu. Seperti diungkapkan McElwain (2008), regulasi pemilu (electoral laws) adalah salah satu pintu masuk terjadinya manipulasi karena regulasi pemilu memiliki dampak keberpihakan (non-neutral). Manipulasi pemilu dapat berhasil memenangkan pihak tertentu melalui regulasi pemilu. Hal itu yang terjadi dalam kasus Pilkada Labuhan Batu Selatan tahun 2015. Regulasi tentang rekrutmen Penyelenggara Pemilu di PKPU No. 2 Tahun 2013 memiliki sejumlah kelemahan (akan dijelaskan kemudian) yang kemudian menjadi sebab kedua terjadinya manipulasi yang berawal dari proses rekrutmen penyelenggara terjadi di Pilkada Labuhan Batu Selatan tahun 2015.

Kelemahan dari PKPU No. 2 Tahun 2013 berkaitan dengan penjelasan di atas. PKPU
No. 2 Tahun 2013 tidak mengatur secara rinci setidaknya tiga hal yang bisa menjadi ruang yang dapat mempengaruhi hasil seleksi, yakni: a. Distribusi soal ujian seleksi yang tidak diterima langsung oleh Tim Seleksi;

b. Ketentuan yang tidak menutup ruang suap terhadap tim seleksi; dan

c. Bias nilai Psikolog dalam ujian Psikologi.

PKPU No. 2 Tahun 2013 tidak mengatur sama sekali tentang bagaimana seharusnya distribusi soal ujian seleksi. Ketiadaan aturan ini sangat mungkin membuka ruang adanya kecurangan sehingga menyebabkan terpengaruhinya hasil seleksi. Kelemahan kedua adalah ketiadaan sama sekali larangan yang dapat menutup ruang suap terhadap tim seleksi. Sama dengan poin tentang distribusi soal ujian seleksi, tak adanya aturan larangan di PKPU No. 2 Tahun 2013 membuat dapat sangat berpengaruh besar terhadap bagaimana hasil seleksi sebelum diserahkan kepada KPU Provinsi untuk kemudian ditindaklanjuti dengan proses wawancara. Begitu pula dengan aturan tentang bagaimana memberi nilai dalam ujian psikolog dan asal dari Psikolog yang tak diatur rinci sama besarnya dalam membuka ruang terjadinya kecurangan yang dapat berpengaruh terhadap hasil seleksi.

\section{SIMPULAN}

Regulasi tentang penyelenggara pemilu tidak serta merta membuat manipulasi dalam pemilu tidak terjadi, termasuk dalam Pilkada tahun 2015. Dalam kasus Labuhan Batu Selatan, artikel ini berpendapat bahwa manipulasi Pilkada di wilayah itu tahun 2015 terjadi disebabkan oleh terdapatnya kepentingan memenangkan petahana. Di samping itu, manipulasi juga terjadi karena didukung oleh adanya kelemahan dalam aturan tentang proses rekrutmen penyelenggara Pilkada.

ini menegaskan bahwa asumsi dan argumentasi tersebut terbukti dalam kasus ini. Tindakan manipulasi dalam Pilkada Labuhan Batu Selatan 2015, yang bertujuan untuk menggagalkan calon lain sehingga kemenangan petahana lebih mudah diraih karena hanya melawan calon "boneka", terjadi karena adanya kepentingan memenangkan petahana dan pasangan calon lain dinilai berpotensi menyulitkan petahanajika tidak digagalkan. Adanya kepentingan petahana 
terjadi sejak proses rekrutmen KPU Labuhan Batu Selatan. Kondisi seperti itu didukung juga oleh adanya kelemahan dalam regulasi pemilu tentang penyelenggara pemilu.

\section{UCAPAN TERIMAKASIH}

Ucapan terima kasih kami tujukan kepada DKPP RI yang mendanai riset ini. Begitu pula kepada Puskapol UI, khususnya Sri Budi Eko Wardani, selaku Direktur Eksekutif saat riset ini kami lakukan, yang memungkinkan kami terlibat di dalamnya.

\section{DAFTAR PUSTAKA}

Alvarez, R. Michael, Thad Hall, dan Susan Hyde (Eds.). (2008). Election Fraud: Detecting and Deterring Electoral Manipulation. Washington DC: Brookings Institution Press.

Anderson, Benedict. (1996). "Election and Participation in Three Southeast Asian Countries." dalam Robert Taylor. The Politics of Elections in Southeast Asia. Cambridge: Cambridge University Press.

Asshiddiqie, Jimly. (2013). Menegakkan Etika Penyelenggara Pemilu. Jakarta: PT RajaGrafindo Persada.

Bachriadi, Dianto, et.al. (2015). Pemenuhan Hak Konstitusional Warga Negara dalam Jakarta: KOMNAS HAM RI.

Beaulieu, Emily dan Susan Hyde. (2009). In the Shadow of Democracy Promotion: Strategic Manipulation, International Observers, and Election Boycotts. Comparative Political Studies. 42 (3). 392-415.

Darwis, Muh. Salman. (2015). Menakar Independensi Penyelenggara Pemilu dalam Pemilihan Kepala Daerah Serentak 2015. Jurnal Etika dan Pemilu 1(2): 22-35.

Elklit, Jorgen dan Palle Svensson. (1997). What Makes Elections Free and Fair?. Journal of Democracy 8 (3): 32-46.

Firman. (2015).Etika Menjaga Netralitas dan Imparsialitas Bagi Birokrasi dan Pimpinan Penyelenggara Pemilu. Jurnal Etika dan Pemilu 1 (3): 20-30.
Goodwin-Gill, Guy S.(2006). Free and Fair Elections: New Expanded Edition, Geneva: Inter-Parliamentary Union.

Hyden, Goran dan Colin Leys. (1972). Elections and Politics in Single-Party Systems: The Case of Kenya and Tanzania" British Journal of Political Science 2 (4): 389-420.

Keputusan DKPP Nomor 70/DKPP-PKEIV/2015, bagian II. Duduk Perkara, Alasan-Alasan dan Pokok Pengaduan Pengadu, point 5, halaman 4 .

Lehoucq, Fabrice. (2003). Electoral Fraud: Causes, Types, and Consequences." Annual Review of Political Science6: 233-256.

Lewis, Paul. (1990). Non-competitive Elections and Regime Change: Poland 1989." Parliamentary Affairs 43: 90-107.

McElwain, Kenneth Mori. (2008). Manipulating Electoral Rules to Manufacture SingleParty Dominance. American Journal of Political Science 52 (1).

Mertens, Donna M. dan Sharlene Hesse-Biber. (2012). Triangulation and Mixed Methods Research: Provocative Positions. Journal of Mixed Methods Research Vol 6 No. 2 : 75-79.

Puskapol UI. (2016). Pemetaan Pelanggaran Etika Penyelenggara Pemilu (20132015). Laporan tidak dipublikasikan.

Renwick, Alan. (2010). The Politics of Electoral Reform: Changing the Rules of Democracy. Cambridge: Cambridge University Press.

Sakwa, Richard dan Martin Crouch. (1978). Elections in Communist Poland: An Overview and Reappraisal.British Journal of Political Science 8 (4): 403-424.

Sarnan, Mukhtar. (2015). Kecurangan dalam Kontestasi Politik: Kasus Pemilukada. Jurnal Etika dan Pemilu 1 (1): 71-86.

Sasongko, Wahyu. (2015). Efektivitas Putusan DKPP.Jurnal Etika dan Pemilu 1 (1): 49-58.

Schedler, Andreas. (2002). Election Without Democracy: The Menu of Manipulation. Journal of Democracy 13 (2): 36-50. 
Simpser, Alberto. (2013). Why Government and Parties Manipulate Elections: Theory, Practice, and Implications, Cambridge: Cambridge University Press.

Taylor, Robert. (1996). "Elections and Politics in Southeast Asia." dalam The Politics of Elections in Southeast Asia. Cambridge: Cambridge University Press.

Yeasmin, Sabina dan Khan Ferdosour Rahman. (2012). 'Triangulation' Research Method as the Tool of Social Science Research. BUP Journal 1(1), 154-163.

Yuningsih, Neneng Yani dan Valina Singka Subekti. (2015). Demokrasi dalam Pemilihan Kepala Desa? Studi Kasus Desa Dengan Tipologi Tradisional, Transisional, dan Modern di Provinsi Jawa Barat Tahun 2008-2013. Jurnal Politik 1(2): 231-261.

Kpu-labuanbatuselatankab.go.id.(2015). Hasil Perhitungan Suara Pilkada Labuan Batu Selatan Tahun 2015, Desember 2016, http://www.kpu-labuhanbatuselatankab. go.id/download/index/Download page/4
Wawancara dengan ENG, mantan penyelenggara pemilu, 2 Agustus 2016.

Wawancara dengan RA, tim sukses salah satu calon bupati, 4 Agustus 2016.

Wawancara dengan $\mathrm{MH}$, tokoh masyarakat Labuhan Batu Selatan, 4 Agustus 2016.

Wawancara dengan $\mathrm{SN}$, tokoh masyarakat Labuhan Batu Selatan, 3 Agustus 2016.

Wawancaradengan MY, mantan penyelenggara pemilu Labuhan Batu Selatan, 3 Agustus 2016.

Wawancara dengan SR, pengurus salah satu parpol di Labuhan Batu Selatan, 4 Agustus 2016.

Wawancara dengan SE, anggota tim seleksi penyelenggara pemilu, 2 Agustus 2016.

Wawancara dengan $\mathrm{J}$, anggota tim seleksi penyelenggara pemilu, 5 Agustus 2016.

Wawancara berkelompok dengan mantan penyelenggara pemilu, 3 Agustus 2016.

Wawancara dengan $\mathrm{ZH}$, pengurus salah satu parpol di Labuhan Batu Selatan, 5 Agustus 2016. 